\title{
ENSINO DE ARTE NO CAMPO DE AÇÃO DA ESTÉTICA RELACIONAL
}

\section{ART TEACHING IN THE FIELD OF RELATIONAL AESTHETICS}

\author{
Francisco Herbert Rolim de Sousa \\ herbertrolim@gmail.com \\ Instituto Federal de Educação Tecnológica do Ceará
}

\begin{abstract}
Resumo:
Este breve estudo procura trazer à tona questões ligadas ao ato de interatuar do artista/professor/pesquisador (IRWIN, 2008; ALMEIDA, 2009) no campo do ensino de Arte, isto é, lançar um olhar prático-reflexivo (PIMENTA, 2005) para ações pedagógicas expandidas (SOUSA, 2013; THISTLEWOOD, 1990) em consonância com a arte contemporânea, no que alcança o sentido de arte pública hoje (DIAS, 2007), de natureza estético-relacional (BOURRIAUD, 2009) e seus efeitos na educação (MORIN, 2010). O objetivo é expor, por meio desta conjunção, ensino de arte e estética relacional, uma possível epistemologia da prática que a reafirme como ação pedagógica e teoria crítica da educação (SAVIANI, 2004). E em suas especificidades, enquanto tal, espera aproximar troca de saberes, experimentações sociais e consciências dos modos de produção.
\end{abstract}

Palavras-chave: experimentação estética, ensino de Arte, estética relacional.

\section{Abstract:}

This study aims to bring to the surface questions related to the artist/teacher/researcher's interaction (IRWIN, 2008; ALMEIDA, 2009) in the field of art education, that is, to throw a practical-reflective look (PIMENTA, 2005) for in the sense of contemporary art (DIAS, 2007), of an aesthetic-relational nature (BOURRIAUD, 2009) and its effects on education (MORIN, 2010). The objective is to expose, through this conjunction, art teaching and relational aesthetics, a possible epistemology of practice that reaffirms it as pedagogical action and critical theory of education (SAVIANI, 2004). And in its specificities, as such, it hopes to bring an exchange of knowledge, social experience and the consciousness of the modes of production.

Keywords: aesthetic experience, Art teaching, relational aesthetics.

\section{Circulação entre intersubjetividade, arte pública e prática pedagógica.}

Com base em algumas experiências de trabalhos práticos reflexivos, este breve estudo procura trazer à tona questões ligadas ao ato de interatuar do artista/professor/pesquisador no campo do ensino de Arte, isto é, lançar um olhar para ações pedagógicas expandidas em consonância com a arte contemporânea, no que alcança o sentido de arte pública hoje, de natureza estético-relacional (BOURRIAUD, 2009) e seus efeitos na educação. O objetivo é expor, por meio 
desta conjunção, ensino de Arte e estética relacional, uma possível epistemologia da prática que a reafirme como prática pedagógica. E em suas especificidades, enquanto tal, espera aproximar troca de saberes, experimentações sociais e consciências dos modos de produção.

Em que aspecto o adjetivo "relacional" pode substantivar a compreensão do que entendemos hoje por arte pública e ensino de Arte? É possível pensar uma arte que esteja mais focada na "formação" do que na "forma"? Podemos falar de uma educação que tenha as relações inter-humanas como meio e fim de sua razão e prática? De quais modi vivendi estamos falando quando se trata de artista/professor/pesquisador no sistema de ensino de Arte? As respostas aqui observadas, considerando os níveis de contextualização e complexidade, partem de conceituações e experimentações que sugerem reflexões.

As observações aqui expostas partem do meu exercício de docência, como artista/professor/pesquisador, ligado ao curso de Licenciatura em Artes Visuais (CLAV) do Instituto Federal de Educação, Ciência e Tecnologia do Ceará (IFCE). Este caráter individual leva em conta o que Edgar Morin considera de mais importante na vida social, que são as relações intersubjetivas:

\begin{abstract}
Uma grande parte, a parte mais importante, a mais rica, a mais ardorosa da vida social, vem das relações intersubjetivas. Cabe até dizer que o caráter intersubjetivo das interaçaões no meio da sociedade, o qual tece a própria vida dessa sociedade, é fundamental. Para conhecer o que é humano, individual, interindividual e social, é preciso unir explicação e compreensão (MORIN, 2010, p. 127).
\end{abstract}

Começo pelo esforço de entrecruzar forças, subjetidades, criação, ensino e teoria, movido pela necessidade de avançar na pesquisa em poética visual, como artista, e de atualizar o conhecimento e a prática pedagógica, enquanto arte/educador: "Do cruzamento entre o que eu faço e o que eu sou desdobram-se forças históricas, afluentes sócio-culturais, subjetividades cúmplices, dígitos pessoais" (DERDYK, 2001, p. 19). Sob essa óptica não há como o pesquisador se distanciar criticamente de seu objeto de estudo; fica explícita sua parcialidade com o campo da episteme, no entando não perde de vista a razão que direciona a pesquisa acadêmica.

\title{
A/r/tografia como ato de conjunções hifenizadas no ensino da arte contemporânea.
}

Em A/r/tografia: uma mestiçagem metonímica, Rita L. Irwin (2008) faz uso da palavra "mestiçagem" no lugar de conexões entre artist-researche-teacher (artista/professor/pesquisador) 
com que "teoria, práxis e poesis, ou teoria/pesquisa, ensino/aprendizado e arte/produção" se entrelaçam. Ainda que resguardadas suas individualidades, essas categorias formam uma unidade dialógica, de espaços entre e dentre as experiências estéticas, as descobertas investigativas e a socialização de conhecimentos.

Artistas-pesquisadores-professores são habitantes destas fronteiras ao re-criarem, repesquisarem e re-aprenderem modos de compreensão, apreciação e representação do mundo. Abraçam a existente mestiçagem que integra saber, ação e criação, uma existência que requer uma experiência estética encontrada na elegância do fluxo entre intelecto, sentimento e prática. (IRWIN, 2008, p. 91).

Nesse território de campos hifenizadas, o que o termo $a / r /$ tografia traz em si é a construção de significados de forma mais potencializada, uma vez que o entrecruzamento da produção de arte, do ensino e da pesquisa não significa negar as diferenças e similaridades dessas categorias, mas pensar numa terceira via, entre margens contaminadas, sem uma correlação demarcada com começo e fim, "mas uma direção perpendicular, um movimento transversal que as carrega uma e outra, riacho sem início nem fim, que rói suas duas margens e adquire velocidade no meio" (p. 36) onde as invenções, as práticas e ideias de cada saber se inter-relacionam.

A/r/tografar significa lidar com os campos da arte, do ensino e da pesquisa, em que as invenções, práticas e ideias de cada saber se interconectam como liame pedagógico de compartilhamento de relações, colocando-se na condição de aprendiz e, com mesmo fôlego, assumindo a responsabilidade da aprendizagem do outro como meio de clarificar conhecimentos adquiridos e formular novas questões. Em última instância é pensar o ensino de Arte como experiência estética.

Em sua tese, que resultou no livro Ser artista, ser professor: razões e paixões do ofício, Célia Maria de C. Almeida (2009) procura compreender e analisar a prática e o pensamento; de que forma se dão as relações entre professores e alunos, sociedade e escola, nesse fazer e refletir. A autora problematiza os espaços de subjetivação, os processos poéticos, as zonas de convergência/divergência, em que predominam a objetividade, a burocracia, a produção quantitativa e a orientação de natureza cartesiana, em se tratando do espaço institucional superior de ensino:

As exigências do tempo do trabalho do artista se distinguem das do tempo do trabalho institucional. Para a instituição, o número de produções importa mais que sua qualidade e relevância. A quantidade exige homogeneização. Na universidade, o trabalho fabril e o artesanal coexistem, e parece que a instituição sempre busca enquadrar o segundo no 
primeiro. Isto ocorre, por exemplo, na avaliação da produtividade: mesmo que o trabalho seja artesanal, a avaliação é massificada. Ao homogeneizar as práticas, a instituição subtrai a especificidade do trabalho do artista e do ensino de arte, daí surge um conflito: o artista anseia o imprevisível pelo intemporal, mas a arte, burocraticamente estabelecida, o aprisiona. (ALMEIDA, 2009, p. 140).

Após se deter em um enumerado de informações e interpretações, motivado por fatos e verbalizações dos professores, com os quais manteve contato em sua pesquisa, Cecília Almeida aponta multifatores tais como conflitos entre uma "concepção programática de formação profissional" (mundo do trabalho) e "ideal humanística" de liberdade criadora; ensinar por uma necessidade de sobrevivência e como meio de manter-se independente do mercado de arte; cerceamento do tempo de pesquisa e produção artística; achatamento salarial; limitações de materiais; instalações não apropriadas; "formulações teóricas sobre como se deve ensinar", desvinculadas da prática; conviver com a opinião daqueles que desvalorizam o trabalho artístico em relação a outros tipos de trabalho por considerar uma atividade livre e criativa; dificuldade dos alunos de admitirem críticas a seus trabalhos ao achar que estas Ihes tiram a espontaneidade; 0 mito do artista como ser inspirado, incapaz de adequar sua natureza criativa ao trabalho sistematizado e institucional etc.

A relação é longa e, como foi dito, multifacetada, por outro lado, as falas dos artistas/professores/pesquisadores, reveladas por Cecília Almeida, também dizem que paralelo a estas limitações "há um campo amplo de decisões que competem a eles exclusivamente: não há interferência na seleção e no desenvolvimento do conteúdo nem na avaliação dos alunos" (ALMEIDA, 2009, p. 142) sobretudo nas instituições públicas, isso cria margens para eles adequarem os projetos de ensino, introduzir conceitos que contribuam com o desenvolvimento de procedimentos estético-visuais e conferir pela prática reflexiva meios de representação que dão sentido à ação educativa.

Ainda na opinião da maioria dos artistas-professores abordados, a pesquisa diz que deve haver equilíbrio entre a aprendizagem de regras, o conhecimento estabelecido e o exercício de criatividade; as informações teóricas e as práticas precisam ser transmitidas de forma sensível, sem imposição de verdades, mas valorizando a inventividade do aluno; os artistas-professores acreditam na força produtiva do ensino; os artistas mantêm na instituição, como professor, o espírito transgressor de negar o sistema, superar seus limites etc. Enfim: "ser artista que educa, ser professor que faz arte" (p. 65). 
Nesse processo a pesquisa aponta referências, orienta e dar razão aos educadores para agirem com consciência e de acordo os objetivos desejados. Para Selma G. Pimenta (2005, p. 26) “o papel da teoria é oferecer aos professores perspectivas de análise para compreenderem os contextos históricos, sociais, culturais, organizacionais e de si mesmos como profissionais, nos quais se dá sua atividade docente, para neles intervir, transformando-os". Em tais circunstâncias, avalia-se que por se tratar, neste caso, da inter-relação de campos singulares e correlacionais, com seus desdobramentos, suas contaminações e suas expansões, faz-se mais ainda necessário estas idas e vindas, em três vias e concomitante, da prática à teoria, da criação à atividade mental, da experiência estética ao ensino.

\section{Por uma experiência estética de ensino de Arte.}

Referência na complexa trama do conceito do que é contemporâneo e suas potencialidades nas práticas estudantis, o pensamento de David Thistiewood ajuda a comprendeender seu sentido, e faz isto pela diferenciação em relação ao termo moderno e o que representa ser vanguarda:

A arte de vanguarda é aquela constituinte da arte 'contemporânea' que acontece na mais avançada linha de frente da prática experimental, exercitando criativas e 'arriscadas' ações/posturas/pensamentos, em busca de novas formas de significação estética. A arte 'contemporânea' consiste na penetração destas novas formas no conhecimento de uma mais ampla audiência, e isto se dá quando camadas de significado são vinculadas a estas novas formas, sucessivamente, por críticos, teóricos e praticantes. $\mathrm{O}$ termo 'moderno' significa um estágio posterior neste processo, quando suficientes camadas de interpretação já foram aplicadas ao 'não tão novo' conceito estético e assim apto a ser empregado em termos mais gerais isto é, na apreciação casual, nos meios de comunicação, na propaganda, e no 'estilo' da cultura como um todo. (THISTIEWOOD, 1990, p. 250)

Com esse ponto de vista, chama atenção para o ensino de Arte ter a responsabilidade de uma consciência crítica diante desse processo, pela abertura de espaços nas escolas para a prática da arte contemporânea, e com isso haver um maior aproveitamento na aprendizagem dos nosso estudantes; um melhor rendimento das práticas experimentais como reflexos dos atores educativos, artistas/professores/pesquisadores e alunos de Arte. Sua orientação parte dos meios 
de ensinar arte contemporânea, no que ela tem de experimental, sem perder de vista a produtividade, o que quer dizer criação de espaços para o exercício do pensamento e experimentação visual, acomodação de subjetividades sem imposição de conceitos dirigidos, e atualização do sentido de estético em relação ao conhecimento adquirido e aquilo que foi produzido:

(...) o que estou sugerindo é um meio de ensinar arte 'contemporânea' produtivamente, baseando-se nos conceitos de construção (de uma experiência prática de arte 'contemporânea') de des-construção do anterior (para acomodar critérios pessoais) e da constante re-construção dos conceitos estéticos resultantes. (pp. 23-24)

Vistas por este ângulo, práticas artísticas/pedagógicas dessa natureza podem contribuir para a construção de camadas de discursos, com as quais a arte contemporânea segue sua tendência natural, com o passar do tempo, de ir se modernizando, na medida em que novos conceitos vão sendo acrescidos aos adquiridos e, aos poucos, sendo assentados até alcançarem a plena aceitação e consenso, como direito universal de acesso no processo de formação do ser humano. Estamos falando de uma abrangência (estética, pedagógica e de métodos de pesquisa) que passa pela "construção" de uma experiência arte-educativa libertadora e crítica; pela "desconstrução" de conceitos pré-estabelecidos para, partindo de subjetivações, a eles voltar e atualizá-los na "reconstrução" de sentidos.

\section{Agenciamento da arte pública relacional pelo ensino de Arte}

Sabemos que o aspecto relacional de uma obra de arte sempre existiu como algo aderente à sua própria condição, isto se considerarmos sua conformação em torno das relações entre artista, obra e espectador, mediadas tradicionalmente por elementos formais fechados, como meio para se chegar a um fim estético. Não obstante, o que chama atenção dos anos 1990 para cá é o grau com que o aspecto relacional passou a dirigir os interesses artísticos, a ponto de ele mesmo ser meio e fim nesse processo de mediação. Em outras palavras, diga-se aqui, não há que se falar em "formas" (elementos visuais, composição, equilíbrio, materiais, suportes etc.) como meio para se chegar ao objeto artístico propriamente dito, mas cabe dizer "formação" 
(comunicacionais, participativos, interativos etc) como meio para se alcançar o que Nicolas Bourriaud chama estética relacional.

Observando as práticas artísticas contemporâneas, deveríamos falar mais em "formações" do que em "formas": ao contrário de um objeto fechado em si mesmo graças a um estilo e a uma assinatura, a arte atual mostra que só existe forma no encontro fortuito, na relação dinâmica de uma proposição artística com outras formações, artísticas ou não. (BOURRIAUD, 2009, p. 29)

Na estética relacional, o projeto de autonomia da arte moderna sofre "uma inversão radical dos objetivos estéticos, culturais e políticos" (p.20) com a qual se distancia dos conceitos de pureza, especificidades internas, estilo e assinatura; em seu lugar emergem valores de forças externas, isto é, "relações entre indivíduos ou grupos, entre o artista e o mundo e, por transitividade, relações entre o espectador e o mundo" (p. 37), enérgias que efetuam espaçostempos relacionais, cuja disposição de produzir e significar não encontra delimitações, margens e fronteiras.

Entenda-se aqui relacional como práticas e teorias artísticas que intermedeiam as relações humanas: "Suas obras lidam com os modos de intercâmbio social, a interação com o espectador dentro da experiência estética proposta, os processos de comunicação enquanto instrumentos concretos para interligar pessoas e grupos" (BOURRIAUD, p. 60). Desse modo os encontros, as reuniões, as celebrações, as festividades, os jogos, as maniestações, qualquer situação de contato podem valer como produção de "forma" de caráter artístico. O artista voltase cada vez mais intencionalmente para "as relações que seu trabalho irá criar em seu público ou na invenção de modelos de socialidade. Essa produção específica determina não só um campo ideológico e prático, mas também novos domínios formais" (p. 40) que extrapolam o que, por muito tempo, tinha-se como simples consumo estético.

Quando falamos de estética relacional estamos falando de uma parte constituinte da arte pública como a entendemos hoje, ainda que o conceito de arte pública abra-se para muitas definições, a exemplo de:

Definir uma arte que seja pública obriga a considerar as dificuldades que rondam a noção deste conceito. Em sentido literal, seriam as obras que pertencem aos museus e acervos, ou os monumentos nas ruas e praças, que são de acesso livre.

(...) O sentido corrente do conceito refere-se à arte realizada fora dos espaços tradicionalmente dedicados a ela, os museus e galerias. Fala-se de uma arte em espaços públicos, ainda que o termo possa designar também interferências artísticas em espaços privados, como hospitais e aeroportos. A ideia geral é que se trata de arte fisicamente acessível, que modifica a paisagem circundante, de modo permanente ou temporário. 
(...) A arte pública deve ser pensada dentro da tendência da arte contemporânea de se voltar para o espaço, seja ele o espaço da galeria, o ambiente natural ou as áreas urbanas. Diante da expansão da obra no espaço, o espectador deixa de ser observador distanciado e torna-se parte integrante do trabalho (neste sentido, difícil parece, algumas vezes, localizar os limites entre arte pública e arte ambiental). ${ }^{1}$

Se essas assertivas não são de todas consensuais, por outro lado, também não são necessariamente excludentes, tendo em comum uma base estrutural que se sustenta na operação de correlações entre "lugar", como espaço socializado; "público", que são seus atores interlocutores; e "identidade", pela qual se põe em ação as relações sociais e simbólicas. Com efeito, a arte pública ao longo de seu decurso histórico pode ser vista a partir de três paradigmas, como observa o antropólogo e curador José António Fernandes Dias (2007), no texto Arte pública: alguns paradigmas:

O primeiro paradigma é o da "arte em espaços públicos", em que o artista está voltado para as qualidades estéticas do objeto artístico, em sua condição de obra autônoma, emoldurada pela paisagem que a circunda "sem que as características particulares do sítio como entidade física, arquitetônica ou geográfica tenha outra importância que não os desafios formais de composição que põem ao escultor" (DIAS, 2007, p. 105).

$\mathrm{Na}$ "arte como espaço público", segundo paradigma, a obra está associada ao ambiente e ao público, o que Ihe confere certas especificidades do lugar como espaço praticado, podendo ser tanto no sentido integrativo e assimilativo como interruptivo e intervencionista, onde se encaixa, por exemplo, o sentido de site-specific (sítio-específico).

Quanto ao terceiro paradigma, "arte no interesse público", as questões de fisicalidade estética cedem às relações entre o ambiente e os agentes culturais, normalmente a partir de projetos temporários feitos com/para o público, que torna-se elemento constituinte de sua poética, "neste sentido, é parte de uma problemática espacio-política, é um discurso que combina ideias acerca da arte, da arquitectura e do design urbano, com teorias da cidade, do espaço social e do espaço público" (p. 109) no âmbito das experimentações sociais de natureza relacional.

\footnotetext{
${ }^{1}$ Transcrições que constam da definição (síntese) de arte pública publicada pelo site do Itaú Cultural com base no pensamento de Annateresa Fabris, Aracy Amaral, Eileen Adams, Harriet Senie, Irving Sandles, Michael Archer, Michael Breson e outros. Cf. Arte Pública. Disponível em: <http://enciclopedia.itaucultural.org.br/termo356/arte-publica $>$. Acesso em jun. 2016.
} 
Como se vê, arte pública não tem assento fixo, seu nomadismo vai de uma arte celebrativa, monumental, a uma arte conceitual; da ideia de forma a um sentido de formação; de um lugar específico à transitoriedade de uma arte desterritorializada; de um tempo congelado a um estado de efemeridade; do simples consumo estético a uma estética relacional; das relações espaço/tempo demarcados aos territórios de convivência sócioespaciais de uma arte que se faz aberta. O importante é se dar conta da presença das relações inter-humanas na arte pública de hoje, como equalizadora entre humanidade e relações humanas. A crítica de arte Lisette Lagnado, depois de observar trinta respostas de artistas, críticos, historiadores e curadores, a respeito do sentido de arte pública faz a seguinte consideração:

trata-se de uma vontade de deselitizar a produção artística, abrindo-a para a participação coletiva, em resposta aos intoleráveis processos de exclusão em curso na sociedade contemporânea. Cresce o tom de defesa da interdisciplinaridade entre as esferas estéticas e sociopolíticas, debate que envolve artistas e não-artistas. ${ }^{2}$

Temos aí, no modo com que essas relações são objetivadas na arte hoje, elementos suficientes para pensar uma teoria da prática educativa que leve em consideração o fenômeno relacional. Para Morin (2010) o problema do ensino está na "compartimentação" e não no "campartilhamento" de saberes, levando em conta a inclinação da mente humana para "contextualizar" e "integrar" - o que explica trazer para este estudo significações, referências e observações que se baseiam em situações de ações relacionais no sentido de abordá-las como prática pedagógica no ensino de Arte.

\section{Ensino de arte em situação de ação estético-relacional.}

Num sentido prático, interligando o que foi dito em termos de artista/professor/pesquisador, estética relacional e ensino de Arte, sublinhamos alguns aspectos do Trabalho de Conclusão de Curso (TCC) do CLAV/IFCE, Os aparecidos políticos: arte ativista, ação educativa e justiça de transição ${ }^{3}$ (2012), do então licenciando, Alexandre de Albuquerque Mourão, sob minha orientação, voltado para sua experimentação estética como elemento de uma teoria prático-educativa em Arte.

\footnotetext{
${ }^{2}$ Matéria publicada na revista Trópico. Disponível em:

$<$ http://www.revistatropico.com.br/tropico/html/textos/956,1.shl > Acesso em jun. 2016.

${ }_{3}$ Trabalho apresentado, em 2012, como conclusão do Curso de Licenciatura em Artes Visuais CLAV/IFCE, como requisito parcial para obtenção do título de Licenciando em Artes Visuais.
} 
Ao investigar suas experiências como licenciando do IFCE e artista junto ao coletivo Aparecidos Políticos ${ }^{4}$, do qual faz parte, Alexandre Mourão se coloca como artista/professor/pesquisador que aciona e articula suas experimentações estéticas, reflexões e práticas adquiridas no CLAV e em sua participação no grupo Meio Fio de Pesquisa e Ação ${ }^{5}$ com a qual deu fôlego à minha tese de doutoramento, Potencialidades da arte pública relacional na arte/educação: práticas da cidade como sala de aula (2012) ${ }^{6}$. Nesse sentido, ajudou a pensar "que a arte pública, relacional, pode ser útil como dispositivo pedagógico e tornar mais interessante e produtivo o ensino e a aprendizagem, o estudo e a pesquisa prática, tanto para o artista/professor/pesquisador quanto para o aluno de arte/educação" (SOUSA, 2009, ii). Alexandre Mourão reflete esse pensamento, na medida em que suas experiências estéticas e as reflexões ao lado d'Os Aparecidos Políticos tiveram como motivação as intervenções urbanas e os questionamentos levantados pelo grupo Meio Fio de Pesquisa e Ação acerca da estética relacional e do ensino de Arte expandido.

O coletivo Aparecidos Políticos tem chamado atenção, nas suas intervenções em algumas cidades do país, para o tema justiça de transição, com trabalhos de pesquisa e ação dirigidos à memória dos mortos e desaparecidos políticos, durante o regime militar no Brasil (1964-1985), objetivando mantê-la, ativa e historicamente, viva. Em sua monografia (TCC), Alexandre Mourão cita, por exemplo, a intervenção urbana Escracho Auditório Castelo Branco (2012), no IFCE, para refletir a relação da educação com a ditadura militar e as implicações de um longo período de violência simbólica e material, apoiando-se nas ideias de Dermeval Saviani, no livro Escola e Democracia (2008) de que trata das teorias da educação, tendo em perspectiva as conexões entre práticas pedagógicas e processo de democratização social, correspondentes a um movimento educativo e político de equalização social.

\footnotetext{
${ }^{4}$ Grupo de artistas "que vem desenvolvendo intervenções urbanas, escraches, grafites, lambe-lambe e rádio livre na luta por memória, verdade e justiça". Tem como proposta "trabalhar numa relação entre a arte e política", do ponto de vista da "arte ativista e ativismo criativo". Disponível em:

$<$ http://www.aparecidospoliticos.com.br/sobre-

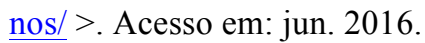

${ }^{5}$ Grupo Meio Fio de Pesquisa e Ação (GMFPA) do Instituto Federal de Educação, Ciência e Tecnologia do Ceará (IFCE) coordenado por mim e "formado por artistas, professores, pesquisadores e licenciandos em arte, com o objetivo de produzir conhecimento sobre as potencialidades da arte pública, relacional, na arte/educação, amenizando os distanciamentos entre arte/educação e arte contemporânea, escola e sociedade". (SOUSA, 2009, ii).

${ }^{6}$ Tese de doutoramento em Belas Artes (Especialidade de Educação Artística), com orientação da Profa. Dra. Margarida Calado, pela Faculdade de Belas Artes da Universidade de Lisboa (FBAUL) e validada pela Universidade Federal de Minas Gerais (UFMG).
} 
Essa ação de arte ativista faz parte da série Rebatismo Popular em que espaços públicos da cidade com nomes de figuras do regime ditadorial passam a ser renomeados com nomes de desaparecidos políticos, dando-Ihes visibilidade, o que aponta para um aparecimento simbólico: "Numa espécie de rito/ação de passagem, acontece o (re)batismo do lugar: os nomes consagrados pelo sistema opressor dão lugar a heróis populares que foram torturados, mortos ou desaparecidos durante tal período (SOUSA, 2013, p. 91). A ação intervencionista do coletivo no Centro Social Urbano Presidente Médici (Figura) é um exemplo, nela o nome do opressor militar foi apagado e em seu lugar foi posto o nome do estudante Edson Luís, morto em 1968, no restaurante Calabouço, Rio de Janeiro, em enfrentamento com a polícia militar.

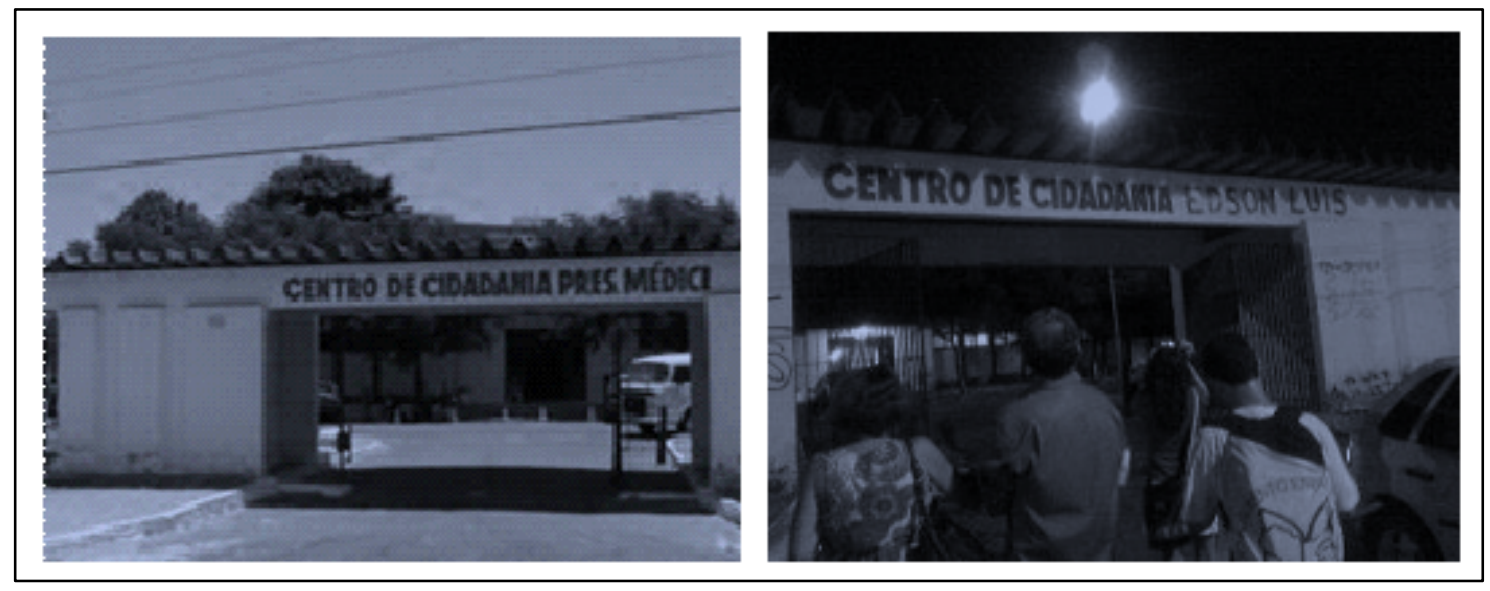

Figura: Coletivo Aparecidos Políticos. Rebatismo . Fortaleza-CE, 2011.

Fonte: Arquivo Aparecidos Políticos.

Em Escracho Auditório Castelo Branco, as reflexões de Alexandre Mourão partem dos pressupostos das "Teorias crítico-reprodutivistas" que pensa e age na educação formal de acordo com as imposições da sociedade organizada, trazendo para a vida escolar a reprodução de seus modelos, com os quais acaba refletindo seus índices de marginalização e gerando a repetição desses fatores. Os seguidores dessa teoria entendem a educação, de acordo com Saviani (2008, p.5), "remetendo-a sempre a seus condicionantes objetivos, isto é, à estrutura socioeconômica que determina a forma de manifestação do fenômeno educativo", assim sendo, pensam a escola como condicionante social, duplicadora das relações de poder ao reproduzir os mecanismos de discriminação e exclusão social, condicionadas pela força capitalista. 
Como parte das "Teorias crítico-reprodutivistas" temos a "Teoria do sistema de ensino como violência simbólica" que quer dizer cristalização cultural das relações de poder sob a orientação da sociedade capitalista. Com base no pensamento de Pierre Bourdieu e J.C. Passeron (1975), exposto na obra A Reprodução: elementos para uma teoria do sistema de ensino, e no sentido que Ihe tomou de empréstimo Dermeval Saviani em Escola e democracia (2008), como violência simbólica, podemos dizer que:

Segundo esta teoria, o sistema de ensino, por infundir de modo subliminar significações de interesse que se ajustam à força material, acaba sedimentando simbolicamente essas relações de poder. Em outras palavras, a violência simbólica na educação nada mais é que a reprodução da subjugação econômica pela dominação cultural, em que se replica na escola o mesmo que acontece na sociedade, num sistema de retroalimentação, por onde se segmentam as relações de força entre dominantes e dominados. (SOUSA, 2013, p. 78)

Enquanto licenciando em Artes e estudante do IFCE, Alexandre Mourão questiona com sua ação interventiva o fato de uma instituição de ensino nomear um dos seus espaços com o nome do primeiro ditador do regime militar, Marechal Castelo Branco. Não seria aí um caso de violência simbólica? Para Dermeval Saviani a violência simbólica configura-se como um modo de organização de relações de força material entre grupos ou classes: "Sobre a base da força material e sob sua determinação, erige-se um sistema de relações de força simbólica cujo papel é forçar, por dissimulação, as relações de força material" (2008, p. 15) de tal forma que a ideologia dominante, pela materialização, exerce seu poder.

Com estas considerações, procuramos chamar atenção para a experiencia estética, a prática educativa e a teoria como indicadores de criação, ações e reflexões, tanto em relação aos conhecimentos adquiridos quanto aos processos de subjetivação com os quais se dão a liberdade de criação e do pensamento criador na construção de novos significados. O exame que fazemos da experiência estética como ensino de Arte, pelo viés do artista/professor/pesquisador, tem a ver com o modo como o individual toca o social; diz respeito à maneira como, enquanto projeto cognitivo de saberes diferentes, articula arte e prática pedagógica e lhes confere sentido ético e de cidadania, com interesse nas inter-relações humanas, de que as experimentações estéticorelacionais e as práticas arte-educativas socioculturais são exemplos, como acabamos de ver.

\section{REFERÊNCIAS}


ALMEIDA, Cecília M. de Castro. Ser artista, ser professor: razões e paixões do ofício. São Paulo: Ed. UNESP, 2009.

BOURDIEU, Pierre; PASSERON, Jean-Claude. A reprodução: elementos para uma teoria do sistema de ensino. Rio de Janeiro: Francisco Alves, 1975.

BOURRIAUD, Nicolas. Estética relacional. Tradução Denise Bottmann. São Paulo: Martins, 2009.

DERDYK, Edith. Linha do horizonte: por uma poética do ato criador. São Paulo: Escuta, 2001.

DIAS, José A. Fernandes. Arte pública: alguns paradigmas. In: Projecto Rio (coodenação Virgínia Fróis). Montemor-o-Novo: Edição Oficinas do Convento, 2007.

IRWIN, Rita L. A/r/tografia: uma mestiçagem metonímica. In: BARBOSA, Ana M.; AMARAL, Lilian (Org). Interterritorialidade: mídias, contextos e educação. São Paulo: Editora Senac São Paulo: Edições SESC SP, 2008.

LAGNADO, Lisette. 0 que é arte pública? Disponível em: <http://www.revistatropico.com.br/tropico/html/textos/956,1.shl >. Acesso em jun. 2016.

MOURÃO, A. Minimanual da arte guerrilha urbana: arte ativista e ação educativa do Coletivo Aparecidos Políticos. 2013. 125 f. Trabalho de Conclusão de Curso (Licenciatura em Artes Visuais) Instituto Federal de Educação, Ciência e Tecnologia. Fortaleza, 2013.

MORIN, Edgar. A cabeça bem feita: repensar a reforma, reformar o pensamento. Tradução Eloá Jacobina. 17. Ed. Rio de Janeiro: Bertrand Brasil, 2010.

PIMENTA, S. Garrido. Professor reflexivo: construindo uma crítica. In: PIMENTA, S. Garrido; GHEDIN, Evandro. (orgs). Professor reflexivo no Brasil: gênese e crítica de um conceito. 3. ed. São Paulo: Cortez, 2005.

SAVIANI, Dermeval. Escola e Democracia. Campinas, SP: Autores Associados, 2008.

SOUSA, Francisco H. Rolim de. Potencialidades da arte pública relacional na arte/educação: práticas da cidade como sala de aula. 2013. 567 f. Tese (Doutorado em em Belas Artes) Universidade de Lisboa, Lisboa, 2013.

THISTLEWOOD, David. Arte contemporânea na educação, construção, desconstrução, reconstrução, reações dos estudantes britânicos e brasileiros ao contemporâneo. In: BARBOSA, A. Mae; SALES, H. Margarida (orgs). $O$ ensino da arte e sua história. São Paulo: MAC/USP, 1990.

Artigo submetido em 11/03/2017, e aceito em 11/03/2017. 